\title{
SUSTENTABILIDADE E SERVIÇO PÚBLICO DE SAÚDE: UMA INTERCONEXÃO NECESSÁRIA
}

\section{Maxwel Mota de Andrade ${ }^{1}$}

\section{RESUMO}

A preservação dos recursos naturais também tem impactado a rotina da Administração Pública, haja vista que a legislação que rege as licitações passou a dar preferência à aquisição de bens e serviços que contemplem aspectos sustentáveis. O objetivo principal deste estudo é averiguar a relação existente entre sustentabilidade e o serviço público de saúde, a partir dos patamares legais e sociais permeados pelo desenvolvimento sustentável. Neste ínterim foi realizada uma pesquisa de natureza exploratória e explicativa por meio de revisão bibliográfica.

Palavras-chave: Administração Pública; Direito à Saúde; Estado; Políticas Ambientalmente Sustentáveis; Sustentabilidade.

\section{SUSTAINABILITY AND PUBLIC HEALTH SERVICE: A NECESSARY INTERCONNECTION}

\begin{abstract}
The preservation of natural resources has also impacted the routine of the Public Administration, given that the legislation that governs tenders has given preference to the acquisition of goods and services that include sustainable aspects. The main objective of this study is to investigate the relationship between sustainability and the public health service, from the legal and social levels permeated by sustainable development. In the meantime, an exploratory and explanatory research was carried out through a bibliographic review.
\end{abstract}

Key words: Public Administration; Right to Health; State; Environmentally Sustainable Policies; Sustainability.

\section{INTRODUÇÃO}

A recente conscientização ambiental das pessoas tem desencadeado discussões acaloradas no mundo acadêmico em torno da necessidade de se rever os padrões de produção e do consumo vigentes no mundo.

Para atender aos atuais desafios do uso excessivo e desordenado dos recursos naturais disponíveis no planeta, surgiu uma infinidade de controles legais, acordos internacionais,

\footnotetext{
${ }^{1}$ Mestrando em Ciência Jurídica pela Universidade do Vale do Itajaí - UNIVALI. Especialização MBA em Parcerias Público-Privadas e Concessões pela Fundação Escola de Sociologia e Política de São Paulo em parceria com a London School of Economics - LSE. Procurador-Geral do Estado de Rondônia. Porto Velho/RO, Brasil. E-mail: maxwel@pge.ro.gov.br.
} 
certificações ambientais, entre outros, criando um círculo virtuoso, onde pessoas, empresas, organismos e entes públicos passaram a empregar modelos de gestão ambiental desenvolvidos, para garantir padrões mínimos de sustentabilidade.

Nessa toada, cabe ao Estado - sentido amplo - contribuir para o processo de consolidação do desenvolvimento sustentável, seja através do controle ou regulação ou por meio de sua atuação como agente de mudança e modelo a ser seguido.

O tema sustentabilidade no serviço público vem ganhando espaço, principalmente na implementação de infraestrutura e de gestão racional de recursos. A exemplo disso, a Lei 8.666/1993, que é a norma geral de licitações e contratos administrativos, foi alterada pela Lei 12.249/2010, passando a incluir como objetivo das licitações públicas a promoção do desenvolvimento nacional sustentável.

A par disso, a legislação brasileira vem nos últimos anos se amoldando aos novos paradigmas da sustentabilidade com vistas a criar na Administração Pública uma cultura de sustentabilidade em suas ações rotineiras, bem como estabelecendo as contratações sustentáveis como objetivo e princípio a ser perquiridos.

O presente artigo busca analisar como os órgãos públicos podem se comportar à frente de novas demandas legais e sociais, que apontam para a exigência de adotar padrões e ações mais sustentáveis nas suas atividades administrativas rotineiras. Já como objetivo específico pretende examinar interconexão entre sustentabilidade e o serviço público de saúde, que transcende o mero atendimento hospitalar.

\section{SUSTENTABILIDADE E ADMINISTRAÇÃO PÚBLICA}

O desenvolvimento nacional indiscutivelmente constitui um dos objetivos perscrutado pela República Federativa do Brasil (artigo $3^{\circ}$, II, CF). No entanto, esse desenvolvimento deve ser associado à elevação da qualidade de vida econômica e social do homem e a erradicação da pobreza (artigo $3^{\circ}$, III e IV, CF), aliado a existência de um meio ambiente ecologicamente equilibrado (artigo 225, caput, $\mathrm{CF}$ ).

Deste modo, diante do relevante cenário surge o desafio de se viabilizar um modelo de desenvolvimento compatível com o direito fundamental ao meio ambiente e aos limites naturais do planeta: um desenvolvimento sustentável. 
A doutora e mestre, Maria Cláudia da Silva Antunes de Souza (2016, p. 248), em conteúdo publicado na Revista Jurídica, apresenta a conexão entre a sustentabilidade e o desenvolvimento sustentável:

Ela tem uma ligação íntima com o “desenvolvimento sustentável”. Normalmente, tem sido aliada às questões ambientais, no sentido de observar-se o padrão de comportamentos até então realizados em determinado ambiente e os mecanismos que passam a compor um sistema para a manutenção adequada e evolução destes mesmos comportamentos, a fim de isentar de prejuízos o ambiente que se pretende manter.

Devido à consciência internacional a respeito da necessidade de preservar o meio ambiente, que teve maiores efeitos nas décadas de 60 e 70, e que resultou na realização da Conferência da ONU sobre Meio Ambiente Humano em 1972, na cidade de Estocolmo, considerado o marco inicial dos encontros envolvendo representantes de diversos países, para a discussão da proteção ambiental.

Duas foram as contribuições fundamentais dessa reunião: a primeira foi a criação do Programa das Nações Unidas para o Meio Ambiente - PNUMA, com o fito de monitorar e promover todas as ações direcionadas à proteção do Meio Ambiente. A segunda refere-se à Declaração de Princípios de Estocolmo (1972) que consagrou princípios axiológicos fundamenteis pelos quais passariam a estruturar os sistemas jurídicos de todos os EstadosPartes. Em seu Princípio, enunciou:

$\mathrm{O}$ homem tem o direito fundamental à liberdade, à igualdade e ao desfrute de condições de vida adequadas em um meio ambiente de qualidade, tal que lhe permita levar uma vida digna e gozar de bem-estar, tendo a solene obrigação de proteger e melhorar o meio ambiente para as gerações presentes e futuras.

A Convenção de Estocolmo apresentou reflexos que se faziam sentir em diversos países, com a adoção de uma tutela protetiva do meio ambiente, quer através de legislações ordinárias, quer através da própria constitucionalização do tema.

Convém observar que inúmeros tratados internacionais seguiram nesta linha, como ocorreu em 1983 com a criação da Comissão Mundial sobre o Meio Ambiente e Desenvolvimento - CMMAD, em que resultou no documento Our Common Future (Nosso Futuro Comum) ou Relatório Brundtland (1987) que definiu o desenvolvimento sustentável, como sendo "aquele que atende as necessidades do presente sem por em perigo a possibilidade de que futuras gerações possam atender as suas", e, em 1992, a Declaração do Rio sobre o Meio Ambiente e Desenvolvimento, proposta pela Organização das Nações 
Unidas (1992) postulou que os seres humanos são o centro das preocupações em relação ao desenvolvimento e possuem direito "a uma vida saudável e produtiva em harmonia com a natureza".

Assim, para que a proteção ambiental seja eficaz, desde a década de 1970, alguns dispositivos legais vêm sendo editados. Nesta linha, pode ser citado como exemplo, o Decreto-Lei $\mathrm{n}^{\circ}$ 1.413, de 14 de agosto de 1975 que impôs às indústrias instaladas ou a se instalarem no território nacional a adoção de medidas, indicadas pelos órgãos governamentais competentes, para prevenir ou corrigir os inconvenientes e prejuízos causados pela poluição e contaminação do meio ambiente (1975).

No âmbito interno brasileiro, a Constituição Federal de 1988, apresenta a proteção ao meio ambiente em muitos dos seus artigos. No artigo $5^{\circ}$, LXXIII, o meio ambiente é citado nos direito e deveres individuais e coletivos (1988):

[...] qualquer cidadão é parte legítima para propor ação popular que vise a anular ato lesivo ao patrimônio público ou de entidade de que o Estado participe, à moralidade administrativa, ao meio-ambiente e ao patrimônio histórico e cultural, ficando o autor, salvo comprovada má-fé, isento de custas judiciais e do ônus da sucumbência.

Acontece que, além da busca pela preservação do meio ambiente, a Constituição Federal brasileira definiu as competências de cada ente da federação. A União, os Estados, o Distrito Federal e os Municípios passaram a possuir competências específicas para legislar sobre determinadas questões ligadas ao desenvolvimento sustentável. O texto constitucional, ao tratar da ordem social, também apresentou um capítulo exclusivo para abordar o meio ambiente.

A proteção ao meio ambiente encontra-se destacado no artigo 225 da Carta Magna (1988):

Art. 225. Todos têm direito ao meio ambiente ecologicamente equilibrado, bem de uso comum do povo e essencial à sadia qualidade de vida, impondo-se ao Poder Público e à coletividade o dever de defendê-lo e preservá-lo para as presentes e futuras gerações.

Impõe-se e decorre do texto do dispositivo constitucional acima, que a manutenção do meio ambiente ecologicamente equilibrado é vista como essencial à sadia qualidade de vida. É notório que o constituinte entendeu-a como bem juridicamente protegido, consoante a Fiorillo (2003, apud SILVA, 2009, p. 105) assegura que: 
[...] a concepção de "essencial à sadia qualidade de vida", vinculada ao direito ambiental, tem como objetivo a tutela do ser humano e, de forma mediata, outros valores que também venham a ser estabelecidos na Constituição Federal. No entendimento do autor, deve-se compreender o que seja essencial, adotando um padrão mínimo de interpretação do art. 225 da Constituição Federal, que não pode estar dissociada do artigo $1^{\circ}$, que trata do princípio da dignidade da pessoa humana, combinado com o artigo $6^{\circ}$, que fixa, no campo dos direitos sociais, um piso vital mínimo, estabelecendo os seguintes direitos: direito à educação, à saúde, ao trabalho, à moradia, ao lazer, à segurança, à proteção, à maternidade e à infância e, no caso dos desamparados, à assistência.

De modo similar, o meio ambiente foi definido como bem constitucionalmente tutelado e de uso comum, inclusive declarado essencial e associado à saúde e à qualidade de vida. Logo existe uma relação direta com o princípio da dignidade da pessoa humana (artigo $1^{\circ}$, III, CF), que deve ser interpretado no seu sentido mais inclusivo de meio ambiente.

À vista disto, o dever e a responsabilidade por sua defesa cabem, de forma conjunta, ao Estado - sentido amplo - e à cidadania, surgindo à necessidade de criação de mecanismos para proteção do meio ambiente.

Maria Claudia da Silva Antunes de Souza (2012, p. 242) acentua:

A proteção do meio ambiente é um dos assuntos mais discutidos nos muitos anos. Atualmente, não é mais um desafio exclusivo para a Ciência Jurídica a criação e a sistematização de normas protetivas do ambiente, pois o caminho mais complexo e relevante a ser trilhado é o conjunto intersistêmico.

A legislação infraconstitucional brasileira buscou efetivar o princípio fundamental de um meio ambiente ecologicamente equilibrado. Assim, pode verifica-se como avanços: o desenvolvimento de processo de gestão ambiental, tais como: reciclagem, educação ambiental, legislação ambiental, licenciamento ambiental, zoneamento ambiental, engenharia ambiental, ecoeficiência, criação de unidades de conservação (parques e reservas nacionais); manejo de bacias hidrográficas, tecnologias limpas, utilização de recursos renováveis, dentre outros.

Segundo leciona Benjamim (2005, p. 64), “o meio ambiente ingressa no universo constitucional em pleno período de formação do Direito Ambiental.” A esse respeito, o autor ainda enfatiza que, “A experimentação jurídico ecológica empolgou, simultaneamente, o legislador infraconstitucional e o constitucional".

Entre os princípios que regem a atividade econômica na Constituição Federal, a busca pela defesa do meio ambiente e a livre concorrência, ambos descritos no artigo 170, a evidenciar a preocupação do Estado com o desenvolvimento sustentável. Acontece que a 
Constituição Federal é a norma de hierarquia superior, prevalece sobre as demais normas, a interpretação das leis por ela recepcionada e que a seguiram e tem que estar em consonância com as suas ordens e princípios.

Há de se mencionar que a proteção ambiental no Brasil não se limita ao texto constitucional, existindo numerosos diplomas legais esparsos que importam com a proteção ambiental, servindo de exemplo à própria Lei de Ação Civil Pública, anterior à Constituição, e que foi devidamente recepcionada pela nova ordem constitucional.

Isso porque, a sustentabilidade e o desenvolvimento sustentável não estão restritos a uma ou outra unidade da Federação. É evidente que a busca por ambos deve ocorrer em todos os lugares, impondo-se, consequentemente, a criação de normas que atinjam todos os Estadosmembros.

Por consequência, o Poder Legislativo, ao elaborar uma norma, deve estar atento à eventual repercussão da matéria (objeto da Lei) no meio ambiente e criar normas que o proteja. Nesse contexto, o Código de Defesa do Consumidor (Lei n 8.078 de 1990), no seu artigo 51, dispõe que "são nulas de pleno direito, entre outras, as cláusulas contratuais relativas ao fornecimento de produtos e serviços que: [...] XIV - infrinjam ou possibilitem a violação de normas ambientais".

$\mathrm{Na}$ perspectiva das compras e serviços públicos, o ponto ideal é que haja a intersecção entre viabilidade, competitividade, impacto ambiental e preço. Nesse contexto, a Lei de Licitações e Contratações Públicas, como é conhecida a Lei ${ }^{\circ}$ 8.666/1993, sofreu alteração por intermédio da Lei $n^{\circ} 12.349 / 2010$ no caput do seu artigo $3^{\circ}$, no qual foi acrescida uma nova destinação às licitações públicas, qual seja, a garantia da promoção do desenvolvimento nacional sustentável (1993):

Art. $3^{\circ}$. A licitação destina-se a garantir a observância do princípio constitucional da isonomia, a seleção da proposta mais vantajosa para a administração e a promoção do desenvolvimento nacional sustentável e será processada e julgada em estrita conformidade com os princípios básicos da legalidade, da impessoalidade, da moralidade, da igualdade, da publicidade, da probidade administrativa, da vinculação ao instrumento convocatório, do julgamento objetivo e dos que lhes são correlatos.

Os padrões de produção e de consumo vigentes (produtor/poluidor e consumidor/consumista), excessivamente prejudiciais ao meio ambiente, devem ser substituídos por padrões sustentáveis, que sejam eficientes na utilização de recursos naturais, 
de infraestrutura e de acesso a serviços básicos. O ponto deixa de ser no consumo e modificase para a cidadania e a preservação com o meio ambiente.

O legislador ao transformar a finalidade da contratação pública da promoção do desenvolvimento nacional sustentável, segundo Irene Patricia Nohara (2016, p. 32) em um princípio elevou a sustentabilidade à categoria de "norma jurídica de caráter geral e elevada carga valorativa", apresentando, portanto, caráter impositivo e vinculante, sob pena de afronta ao princípio da legalidade.

O Acórdão $n^{\circ}$ 1752/2011 do Tribunal de Contas da União (2011, p. 391) sinaliza o que é esperado do papel do gestor público, no tocante às contratações com critérios de sustentabilidade:

O consumo mais responsável é condição indispensável para uma economia de baixo
carbono, baseada na sustentabilidade, e o Estado tem o papel fundamental no
fomento de um padrão de consumo mais racional, impulsionando o mercado e a
sociedade a refletir e adotar novos hábitos e valores. (...) A finalidade da
Administração Pública é por em prática as políticas públicas e programas de
governo. Para isso, é preciso gastar, mas deve fazê-lo de forma eficiente e
sustentável, com zelo e austeridade, a fim de atender às necessidades da sociedade
sem deixar de preservar o meio ambiente. Gerir bem os recursos financeiros e
naturais é obrigação de todo e qualquer agente público.

Isso não implica, necessariamente, em maiores gastos de recursos públicos, pois a caraterização de uma contratação sustentável, a caracterização da vantagem da proposta deve ser conjugada com a avaliação do ciclo de vida do produto/serviço, optando-se por aquele que acarrete o menor impacto ambiental no processo de fabricação, consumo e destinação final, conforme previsão contida no artigo $1^{\circ}$ da Instrução Normativa (IN) $n^{\circ} 01 / 2010$, da Secretaria de Logística e Tecnologia da Informação do Ministério do Planejamento, Orçamento e Gestão - SLTI/MPOG (2010):

Art. $1^{\circ}$ Nos termos do art. $3^{\circ}$ da Lei $n^{\circ} 8.666$, de 21 de junho de 1993 , as
especificações para a aquisição de bens, contratação de serviços e obras por parte
dos órgãos e entidades da administração pública federal direta, autárquica e
fundacional deverão conter critérios de sustentabilidade ambiental, considerando os
processos de extração ou fabricação, utilização e descarte dos produtos e matérias-
primas. Tal norma é de aplicação obrigatória apenas no âmbito da Administração Pública Federal Direta, Autárquica e Fundacional. Todavia, caso não exista regulamentação nas esferas estaduais e municipais, nada impede que outros órgãos adotem a mesma como 
parâmetro para disciplinar suas contratações públicas sustentáveis, indicando, dessa forma os critérios a serem utilizados nas contratações.

As contratações públicas sustentáveis contribuem efetivamente para a reorganização da economia com novos paradigmas. No Brasil, direcionam as ações e políticas para o desenvolvimento sustentável, ou seja, conforme dispõe Maria Claudia da Silva (2016, p. 249) "tem como objetivo definir um modelo econômico capaz de gerar riquezas e bem-estar, concomitantemente que fomente a coesão social e impeça a degradação do ambiente".

Com efeito, as compras públicas se tornaram uma intensa ferramenta de indução de mercado, pois no Brasil movimentam recursos estimados de $10 \%$ a $15 \%$ do Produto Interno Bruto (PIB), mobilizando setores importantes da economia que se ajustam às demandas previstas nos editais de licitação pelo país a fora, conforme Ministério do Planejamento.

Ademais, importante salientar que apesar de a Lei $n^{\circ} 8.666 / 1993$ ser a principal norma reguladora de licitações e contratos administrativos em todas as esferas da Administração Pública, ela não é a única. Vários dispositivos de nosso ordenamento jurídico determinam requisitos a que o gestor deve se atentar no momento da contratação, especialmente no que se refere à preocupação ambiental.

A promoção de prática de contratações públicas sustentáveis, no Brasil, realiza-se gradativamente mediante alterações na legislação.

O Decreto $n^{\circ} 7.746$ de 2012, por exemplo, criou o Plano de Gestão de Logística Sustentável (PSL) e no artigo 16 (2012) suscita o compromisso da "administração pública federal direta, autárquica e fundacional e as empresas estatais dependentes deverão elaborar e implementar Planos de Gestão de Logística Sustentável".

Os gestores públicos no âmbito da União passaram a ter que se atentar para racionalização de gastos e imprimir soluções sustentáveis em suas ações. Nessa linha de raciocínio, o Tribunal de Contas da União - TCU (2017, p. 3), na fiscalização dos atos da Administração Federal, criou o Índice de Acompanhamento da Sustentabilidade na Administração (IASA), método de avaliação da implementação e gestão das práticas de sustentabilidade. O IASA trabalha com uma escala de avaliação de 0 a 3 (zero a três), que permite classificar a efetivação das medidas sustentáveis em três faixas: vermelho, amarelo e verde, correspondentes, respectivamente, aos níveis baixo, médio e alto de implementação e de gestão dessas práticas. 
Foram adotados onze eixos temáticos da sustentabilidade, divididos, de acordo com o que segue: 1) elaboração, implementação e monitoramento do PLS; 2) racionalização no uso de energia elétrica; 3) racionalização no uso de água; 4) atendimento a requisitos de acessibilidade; 5) certificação de prédios públicos; 6) racionalização no uso de papel e implementação de processo eletrônico; 7) gestão de resíduos e coleta seletiva; 8) contratações sustentáveis; 9) mobilidade e gases de efeito estufa; 10) conscientização e capacitação; e, 11) adesão ao programa de sustentabilidade.

Em 2011 foi promulgada a Lei Federal $n^{\circ}$ 12.462, que instituiu o Regime Diferenciado de Contratações Públicas (RDC), com expressa adoção de licitações sustentáveis. Não obstante o RDC ser aplicado somente às licitações relacionadas no artigo $1^{\circ}$ é de grande abrangência, já que deve ser aplicado, por exemplo, as obras do PAC, unidades de atendimento socioeducativo e sistemas públicos de ensino e, nas obras e serviços de engenharia no âmbito do Sistema Único de Saúde.

A referida lei ainda prevê a promoção do desenvolvimento nacional sustentável, como um de seus objetivos e permite que seja estabelecida remuneração variável vinculada ao desempenho da contratada, com base em critérios de sustentabilidade ambiental. Além disso, pela primeira vez uma norma de licitação menciona a necessidade de avaliação dos custos diretos e indiretos e os impactos causados pelas obras públicas em longo prazo.

Neste ínterim, cabe à todas as esferas da Administração Pública o compromisso de contribuir no enfrentamento das questões ambientais, buscando estratégias inovadoras que repensem os atuais padrões de produção e consumo, os objetivos econômicos, incluindo componentes sociais e culturais. Barki (2011, p. 3.965) destaca que "o Estado como consumidor tem o potencial de fomentar o mercado, e como empregador o de imprimir uma cultura administrativa sustentável”.

Influenciado pela legislação federal a Lei Complementar do Estado de Rondônia, $\mathrm{n}^{\circ}$ 1.051, de 12 de dezembro de 2019, que disciplina a locação de imóveis sob medida, no âmbito da Administração Direta e Indireta, em seu artigo $8^{\circ}, \S 1^{\circ}$, VI, adotou requisitos de sustentabilidade ambiental nos editais para esse objeto (2019).

O Estado de Rondônia também, através do Decreto n ${ }^{\circ}$ 21.794, de 5 de abril de 2017, instituiu o programa "Governo Sem Papel” com o objetivo de eliminar gradualmente o trâmite de papel, adotando o Sistema Eletrônico de Informações (SEI), desenvolvido pelo Tribunal Regional Federal da $4^{\mathrm{a}}$ Região - TRF4 (2017). 
Não obstante o arcabouço jurídico sobre o tema sustentabilidade, as iniciativas sustentáveis no serviço público ainda são tímidas. Entretanto, é possível romper com o círculo vicioso existente e engajar gestores e servidores em ações pautadas pela co-responsabilização e compromisso com a defesa do meio ambiente a partir de interdependência com áreas específicas, como o serviço de saúde.

\section{DESAFIOS E POSSIBILIDAdeS DE UM SERVIÇO PÚBLICO DE SAÚDE SUSTENTÁVEL}

A saúde consta expressamente na Declaração Universal dos Direitos Humanos DUDH, proclamada pela Assembleia Geral das Nações Unidas em Paris, em 10 de Dezembro de 1948 (Resolução 217 A-III), criada para definir os direitos de todos à vida, à justiça, à educação, à segurança, quando o mundo vivia a ressaca do fim da Segunda Guerra Mundial, que terminou oficialmente em 1945.

A ideia do direito à saúde como um direito fundamental aparece no artigo 25 da DUDH, abaixo transcrito (ONU, 1948):

Toda a pessoa tem direito a um nível de vida suficiente para lhe assegurar e à sua família a saúde e o bem-estar, principalmente quanto à alimentação, ao vestuário, ao alojamento, à assistência médica e ainda quanto aos serviços sociais necessários, e tem direito à segurança no desemprego, na doença, na invalidez, na viuvez, na velhice ou noutros casos de perda de meios de subsistência por circunstâncias independentes da sua vontade.

A DUDH surgiu como resposta às atrocidades cometidas durante o período que vigorou o nazismo e detinha como finalidade maior, unir todos os Estados e estabelecer em conjunto os direitos humanos. Por isso, a elevação dos direitos humanos ao nível internacional passou a significar que o comportamento dos países não é mais governado apenas por padrões locais, bem como esses direitos não podem ser esquecidos por conveniência, política ou militar.

Assim, o direito à saúde como um direito humano reconhecido pela comunidade internacional, aplica-se absolutamente a todas as pessoas, de forma igualitária, descartando qualquer tipo de distinção referente à raça, cor, sexo, independentemente de sua vinculação com determinada ordem constitucional (PEREIRA, 2006, p. 77). 
No contexto brasileiro, o direito à saúde foi inserido na Constituição Federal de 1988, primeiramente, no título destinado aos direitos e garantias fundamentais. Nessa perspectiva, a nossa Carta Política, no seu artigo $6^{\circ}$, estabelece como direitos sociais fundamentais; a educação, a saúde, o trabalho, o lazer, a segurança, a previdência social, a proteção à maternidade e à infância.

A Constituição Federal vigente trata o direito à saúde como direito fundamental acessível a todos, sem qualquer distinção, de forma universal, integral, gratuito e igualitário, da qual a promoção tornou-se dever do Estado (artigo 196). Nasce, então, um novo conceito de serviço público de saúde em substituição ao modelo de acesso restrito aos trabalhadores com carteira assinada, vigente até 1988.

O Ministro Barroso (2008, p. 98), em publicação anterior a sua nomeação ao Supremo Tribunal Federal, concluiu que:

Com a redemocratização, intensificou-se o debate nacional sobre a universalização
dos serviços públicos de saúde. O momento culminante do "movimento sanitarista"
foi a Assembleia Constituinte, em que se deu a criação do Sistema Único de Saúde.
A Constituição Federal estabelece, no art. 196, que a saúde é "direito de todos e
dever do Estado", além de instituir o "acesso universal e igualitário às açães e
serviços para sua promoção, proteção e recuperação". A partir da Constituição
Federal de 1988, a prestação do serviço público de saúde não mais estaria restrita
aos trabalhadores inseridos no mercado formal. Todos os brasileiros,
independentemente de vínculo empregatício, passaram a ser titulares do direito à
saúde.

Sucedeu que posteriormente, foi estabelecido o arcabouço legal desse novo modelo denominado Sistema Único de Saúde - SUS. A nova normatização manifestou uma revolução no sistema público de saúde, acessível a todos, competindo ao Estado custeá-lo. Acontece que o novo sistema apresentou também, princípios de gestão para a boa prestação dos serviços, abrangendo a melhor gestão dos insumos, serviços e bens de saúde, pelos estabelecimentos públicos.

A Lei 8.080, de 19 de setembro de 1990, instituiu o SUS, assim como estabelece normas, deveres e obrigações para o Estado em suas várias esferas, como também para a iniciativa privada que deve atuar de forma complementar ao serviço público. É importante mencionar que a Lei possui abrangência no âmbito nacional, e norteia vários aspectos da saúde chegando ao cunho social (1990).

Constata-se que na Lei retro, em seu artigo $2^{\circ}$, o direito à saúde é tratado como um direito fundamental de todos e no artigo $3^{\circ}$, observar-se uma inter-relação com o meio 
ambiente para a boa manutenção da saúde humana, sendo ainda considerados fatores determinantes e condicionantes, o meio ambiente, como observada a seguir (1990):

\begin{abstract}
A saúde tem como fatores determinantes e condicionantes, entre outros, a alimentação, a moradia, o saneamento básico, o meio ambiente, o trabalho, a renda, a educação, o transporte, o lazer e o acesso aos bens e serviços essenciais; os níveis de saúde da população expressam a organização social e econômica do País.
\end{abstract}

Já no artigo $6^{\circ}$ da mesma Lei prevê que poderá ser foco de atuação do SUS, as ações do meio ambiente que interfiram na saúde, "estão incluídas ainda no campo de atuação do Sistema Único de Saúde (SUS): a participação na formulação da política e na execução de ações de saneamento básica e a colaboração na proteção do meio ambiente, nele compreendido o do trabalho" (1990).

A Organização Mundial de Saúde - OMS (1946), define saúde como "estado de completo bem-estar físico, mental e social" e o afastamento desse estado caracteriza o adoecimento, com diversos fatores que atuam e determinam esse processo que se denomina saúde-doença.

Para uma perfeita análise do tema, imperiosa a própria definição de saúde no dicionário brasileiro da Língua Portuguesa (2021):

1 Estado do organismo com funções fisiológicas regulares e com características estruturais normais e estáveis, levando-se em consideração a forma de vida e a fase do ciclo vital de cada ser ou indivíduo.

2 Bem-estar físico, psíquico e social.

3 Vigor físico, energia, força, robustez.

Veja, o direito à saúde não se restringe apenas ao atendimento hospitalar. Não obstante o acesso aos serviços médico-hospitalares tenha relevância, como direito fundamental, o direito à saúde implica também na garantia ampla de qualidade de vida, em associação a outros direitos sociais básicos.

Nos dizeres de Dalmo de Abreu Dallari (2004, p. 78):

[...] o direito à saúde é um dos direitos fundamentais dos seres humanos, porque sem esse direito ninguém consegue viver com bem-estar e realizar tudo o que é necessário para que uma pessoa seja feliz. Além disso, a pessoa sem saúde não pode ajudar as outras pessoas a conquistarem o seu bem-estar. Por todos esses motivos, uma sociedade só poderá ser considerada justa se todas as pessoas, sem nenhuma exceção, tiverem efetivamente assegurado seu direito à saúde desde o primeiro instante de vida. 
No ano de 1995, o Brasil aderiu à Carta Pan-Americana sobre Saúde e Ambiente no Desenvolvimento Sustentável, em Washington, representado pelo Ministério da Saúde e do Meio Ambiente. Ocorre que a ratificação dessa Carta veio, no mesmo ano, com o Plano Nacional de Saúde e Ambiente no Desenvolvimento Sustentável, pelo Ministério da Saúde, aos quais abarcam diretamente as relações saúde e ambiente, saneamento e recursos hídricos.

Acontece que este plano tem como princípios a universalização, equidade e integralidade, oriundos da reforma sanitária, e alguns princípios da política nacional do meio ambiente, como o princípio do desenvolvimento sustentável. Objetivando a garantia de todos os cidadãos, à saúde e ao meio ambiente equilibrado e saudável, a impressão de diversas ações integradoras entre a saúde e meio ambiente; tendo como meta minimizar os efeitos adversos da poluição nos seres humanos, impedimento de doenças degenerativas e a disseminação de doenças transmissíveis, bem como a promoção da articulação intersetorial de saneamento, de acordo com Ministério da Saúde (1995, p. 104).

A saúde e o meio ambiente estão inseridos na Constituição Federal sob o mesmo Título VIII, da ordem social, determinando em seus arts. 196 e 225 que, ambos são direitos de todos e dever do Estado, correspondentemente colocados um como condição do outro ao estabelecer que o meio ambiente, ecologicamente equilibrado é essencial para a sadia qualidade de vida, em uma relação de interdependência que caracteriza expressamente a abordagem antropocêntrica do meio ambiente, na Carta Magna brasileira.

Canotilho e Leite (2007, p.93) afirmam que:

Em outras palavras, a aceitação de uma proteção autônoma do meio ambiente em muitas situações não exclui, e até recomenda, sua conexão com a saúde e segurança humanas.

Exatamente por despertar essa reverência tradicional por parte do legislador e do implementador, decorrência de seu prestígio na opinião pública, o argumento da proteção da saúde oferece benefícios inegáveis à tutela do meio ambiente, já que consigo transportar força retórica e visibilidade inigualáveis.

A promoção de um meio ambiente sustentável, portanto, necessita ser permeada pela igual promoção do direito à saúde, uma vez que é de notório conhecimento que um ambiente, que seja adequadamente protegido e que forneça as condições mínimas de sustentabilidade, interfere na condição de saúde da população como um todo.

O Conselho Nacional de Saúde (2007) relacionando saúde e sustentabilidade ambiental, assim expõe: 


\begin{abstract}
A exploração da interface entre saúde e ambiente, sob o marco da sustentabilidade, compreende a instituição de uma política que expresse a multiplicidade de forças interativas geradas em torno da promoção do bem-estar e da saúde humana.

Dessa forma, iniciativas para o desenvolvimento socioeconômico, realizadas em parceria, propiciarão uma visão sistêmica de "co-responsabilidade". As comunidades e os indivíduos engajados na promoção do desenvolvimento podem fortalecer os vínculos institucionais com processos de pactuação coletivos e democráticos.
\end{abstract}

Nesse sentido, é imperioso destacar que a Política Nacional de Resíduos Sólidos, instituída por meio da Lei Federal n 12.305/2010, reúne o conjunto de princípios, objetivos, instrumentos, diretrizes, metas e ações adotadas pelo Governo Federal, isoladamente ou em regime de cooperação com os demais entes públicos ou particulares, com vistas à gestão integrada e ao gerenciamento ambientalmente adequado dos resíduos sólidos.

Consequentemente ao adotar um sistema adequado de manejo e gerenciamento dos resíduos sólidos de saúde, possibilita controlar e reduzir com segurança e economia os riscos para a saúde e meio o ambiente; provocados por estes resíduos. Por outro lado, o tratamento e destinação incorretos desses resíduos, além de infringir a legislação ambiental, estes podem gerar inúmeras doenças.

Ocorre que o desenvolvimento sustentável de um Estado ou organismo abarca não apenas o atendimento das normas de proteção ambiental, pois requer também, planejamento quanto ao consumo racional, licitações e aquisições sustentáveis, desenvolvimento de tecnologias que poupem recursos naturais, política voltada para o desenvolvimento econômico sustentável dentre outros fatores.

Um serviço público de saúde é sustentável, por exemplo, quando é devidamente dimensionado a oferta na equivalente medida da demanda, com estruturas e processos de trabalho essenciais à segurança assistencial, entre eles o manejo dos seus resíduos que, se inadequado, expõe a organização a gastos extras, acidentes de trabalho, processos judiciais por infecções hospitalares e etc.

Assim, um dos maiores desafios para os gestores públicos é, essencialmente como sair do plano teórico-conceitual, para o nível prático e estabelecer a harmonia entre os diversos elementos exigidos nos três pilares fundamentais da sustentabilidade: o ambiental, o social e o econômico.

Diante do cenário atual, o qual sugere uma atuação do Estado pautado na resolução dos problemas da saúde pública e meio ambiente que reflita a realidade do desenvolvimento sustentável, à vista disto, faz necessário trazer à acepção de Zygmunt Bauman (1999, p. 30): 
Não admira que a legibilidade do espaço, sua transparência, tenha se transformado num dos maiores desafios da batalha do Estado moderno pela soberania de seus poderes. Para obter controle legislativo e regulador sobre os padrões de interação e lealdade sociais, o Estado tinha que controlar a transparência do cenário no qual vários agentes envolvidos na interação são obrigados a atuar. A modernização dos arranjos sociais promovidos pelas práticas dos poderes modernos visava ao estabelecimento e perpetuação do controle assim entendido. Um aspecto decisivo do processo modernizador foi portanto a prolongada guerra travada em nome da reorganização do espaço.

Sustentabilidade é um conceito a ser incorporado ao dia a dia das instituições, especialmente as da área de saúde pública que convive com recursos escassos e uma demanda crescente, por isso o Poder Público deve assumir o papel de fomentador de políticas ambientalmente sustentáveis, devido ao significativo volume de aquisições e contratações de serviços e obras públicas.

Insta salientar, que para que atinja um nível de desenvolvimento sustentável que não seria necessário parar de crescer economicamente, mas que se produzisse e consumisse com consciência, respeitando os limites do Planeta, seria necessária uma atuação conjunta, não só do poder público, mas de toda a sociedade. É o que se percebe nas palavras de Maria Cláudia e Pasold (2017, p. 57):

Posto que todo homem tem o dever de preservar o meio ambiente para garantir a perpetuação da espécie humana e de todas as outras, bem como do próprio planeta, e essencial o conhecimento de como faze-lo, e, nesta situação, o saber une-se ao fazer. Será, então, por meio dela que as presentes e futuras gerações poderão ter seus direitos assegurados, em especial os direitos a um meio ambiente ecologicamente equilibrado e a sadia qualidade de vida.

À medida que se consolida, o paradigma da sustentabilidade no serviço público aumenta a necessidade dos gestores trabalharem estratégias para sua efetiva operacionalização. Tem que se modificar o planejamento e as práticas da gestão, fortalecer a participação social, modificar hábitos e costumes, valorizar o meio natural, a cultura e promover a equidade, para que se consiga alcançar um meio-ambiente ecologicamente equilibrado - essencial à sadia qualidade de vida.

\section{CONSIDERAÇÕES FINAIS}

O tema da sustentabilidade na Administração Pública se ampara em acordos internacionais, na Constituição Federal e na legislação infraconstitucional. Seu principal 
objetivo é reduzir a pressão sobre os recursos naturais, que são finitos, fomentar uma mudança de cultura no mercado, a partir do seu poder de compra, impulsionando ações mais sustentáveis na sociedade e a promoção da saúde.

Nesse contexto, verifica-se que no dever constitucional de fornecimento de um serviço público de saúde, universal e igualitário, está também incluso o dever do Poder Público proporcionar um meio ambiente ecologicamente equilibrado, com uma atuação que contribua para uma sadia qualidade de vida da população.

Assim, a saúde e meio ambiente são direito inseparáveis da tutela da vida humana digna, motivo pelo qual a ordem econômica não pode jamais olvidar de tais fatores, por ser indispensável à sadia qualidade de vida da população.

A sustentabilidade, por outro lado, não se limita apenas aos aspectos legais relacionados a proteção ao meio ambiente, mas devem ser considerados todos os seus aspectos. Logo, as ações a serem desempenhadas pelos agentes públicos requer um adequado planejamento, como por exemplo, quanto ao consumo racional e geração de resíduos, bem como licitações sustentáveis e utilização de tecnologias como alternativas para redução dos impactos negativos no meio ambiente.

O desafio para implantação de ações mais sustentáveis na rotina do serviço público de saúde é enorme; envolve variáveis institucionais e legais, a ausência de capacitação dos agentes públicos, além das limitações orçamentárias.

Portanto, almeja-se que as iniciativas a serem estabelecidas no âmbito governamental consigam obter um alcance ampliado, com foco na interface existente entre ambiente, promoção da saúde e sustentabilidade, com vistas a emponderá-los na direção de que os mesmos sejam atores, mediadores e protagonistas de ações que visem à melhoria das condições de vida das gerações futuras.

\section{REFERÊNCIAS BIBLIOGRÁFICAS}

BRASIL. Lei $\mathrm{n}^{\circ}$ 8.080, de 19 de setembro de 1990. Dispõe sobre as condições para a promoção, proteção e recuperação da saúde, a organização e o funcionamento dos serviços correspondentes e dá outras providências. Disponível em: <http://www.planalto.gov.br/ccivil 03/leis/18080 > . Acesso em: 26 de setembro de 2020.

RONDÔNIA. Decreto n. 21.794, de 5 de abril de 2017. Dispõe sobre o uso do Sistema Eletrônico de Informações para realização do processo administrativo no âmbito do 
Poder Executivo incluindo os Órgãos e as Entidades da Administração Pública Estadual Direta e Indireta e dá outras providências. Disponível em <http://ditel.casacivil.ro.gov.br/COTEL/Livros/detalhes.aspx?coddoc=27527>. Acesso em: 25 de setembro de 2020.

BRASIL. Decreto n. 21.794, de 5 de abril de 2017. Dispõe sobre o uso do Sistema Eletrônico de Informações para realização do processo administrativo no âmbito do Poder Executivo incluindo os Órgãos e as Entidades da Administração Pública Estadual Direta e Indireta e dá outras providências. Disponível em $<$ http://ditel.casacivil.ro.gov.br/COTEL/Livros/detalhes.aspx?coddoc=27527>. Acesso em: 25 de setembro de 2020.

BRASIL. Decreto $n^{\circ} 7.746$, de 5 de junho de 2012. Regulamenta o art. $3^{\circ}$ da Lei $\mathbf{n}^{\circ} \mathbf{8 . 6 6 6}$, de 21 de junho de 1993, para estabelecer critérios e práticas para a promoção do desenvolvimento nacional sustentável nas contratações realizadas pela administração pública federal direta, autárquica e fundacional e pelas empresas estatais dependentes, e institui a Comissão Interministerial de Sustentabilidade na Administração Pública CISAP. Disponível em: <http://www.planalto.gov.br/ccivil_03/_ato20112014/2012/decreto/d7746.htm>. Acesso em: 23 de setembro de 2020.

BRASIL. Instrução Normativa ${ }^{\circ}$ 01, de 19 de janeiro de 2010 - Secretaria de Logística e Tecnologia da Informação do Ministério do Planejamento, Orçamento e Gestão (MPOG). Dispõe sobre os critérios de sustentabilidade ambiental na aquisição de bens, contratação de serviços ou obras pela Administração Pública Federal direta, autárquica e fundacional e dá outras providências. Brasília, DF, 19 jan. 2010.

BARKI, Teresa Villac Pinheiro. Direito internacional ambiental como fundamento jurídico para as licitações sustentáveis no Brasil. In: SANTOS, Murillo Giordan; BARKI, Teresa Villac Pinheiro (Coord.). Licitações e contratações públicas sustentáveis. Belo Horizonte: Fórum, 2011.

BARROSO, Luís Roberto. Da falta de efetividade à judicialização excessiva: direito à saúde, fornecimento gratuito de medicamentos e parâmetros para atuação judicial. Porto Alegre: Revista da Procuradoria-Geral do Estado, 2008.

BAUMAN, Zygmunt. Globalização: As Consequências Humanas. Tradução de Marcus Penchel. Rio de Janeiro: Editora Jorge Zahar, 1999.

BRASIL. Conselho Nacional de Saúde. Subsídios para construção da Política Nacional de Saúde Ambiental. Brasília: Editora do Ministério da Saúde, 2007.

BRASIL. Constituição da República Federativa do Brasil de 1988. Disponível em: <http://www.planalto.gov.br/ccivil_03/Constituicao/Constituicao.htm>. Acesso em: 15 de setembro de 2020.

BRASIL. Lei $\mathrm{n}^{\circ} 12.305$ de 02 de agosto de 2010. Institui a Política Nacional de Resíduos Sólidos; altera a lei $\mathrm{n}^{\circ} \mathbf{9 . 6 0 5}$, de 12 de fevereiro de 1998; e dá outras providencias. 
Disponível em: <http://www.planalto.gov.br/ccivil_03/_ato2007-2010/2010/lei/112305>. Acesso em: 27 de setembro de 2020.

BRASIL. Lei $\mathrm{n}^{\circ} 12.462$, de 05 de agosto de 2011. Institui o Regime Diferenciado de Contratações Públicas - RDC e dá outras providências. Disponível em: $<$ http://www.planalto.gov.br>. Acesso em: 24 de setembro de 2020.

BRASIL. Lei ${ }^{\circ}$ 8.078, de 11 de setembro de 1990. Código de Defesa do Consumidor. Dispõe sobre a proteção do consumidor e dá outras providências. Disponível em: <http://www.planalto.gov.br/ccivil_03/Leis/L8078.htm>. Acesso em: 25 de setembro de 2020.

BRASIL. Lei $\mathrm{n}^{\circ}$ 8.080, de 19 de setembro de 1990. Dispõe sobre as condições para a promoção, proteção e recuperação da saúde, a organização e o funcionamento dos serviços correspondentes e dá outras providências. Disponível em: <http://www.planalto.gov.br/ccivil_03/leis/18080>. Acesso em: 26 de setembro de 2020.

BRASIL. Lei $\mathrm{n}^{\circ}$ 8.666, de 21 de junho de 1993. Regulamenta o art. 37, inciso XXI, da Constituição Federal, institui normas para licitações e contratos da Administração $\begin{array}{lllll}\text { Pública d d e } & \text { outras } & \text { providências. } & \text { Disponível }\end{array}$ em:<http://www.planalto.gov.br/ccivil_03/Leis/L8666cons.htm> Acesso em: 24 de setembro de 2020.

BRASIL. Ministério da Saúde. Plano Nacional de Saúde e Ambiente no desenvolvimento sustentável. Diretrizes para a implementação. Brasília: Ministério da Saúde, 1995.

BRASIL. Ministério do Planejamento. Contratações públicas sustentáveis. Disponível em: $<$ http://cpsustentaveis.planejamento.gov.br/contratacoespublicassustentaveis\#: :text=As\%20contrata\%C3\%A7\%C3\%B5es\%20governamentais $\% 2 \mathrm{C}$ $\% 20$ no $\% 20$ Brasil, $\% 2 \mathrm{C} \% 20 \mathrm{o} \% 20 \% \mathrm{C} 3 \%$ A9tico\%2C\%20entre\%20outros $>$. Acesso em: $11 \mathrm{de}$ novembro de 2020 .

BRASIL. TRIBUNAL DE CONTAS DA UNIÃO - TCU. Sustentabilidade na Administração Pública Federal. Relator Ministro-Substituto André Luís de Carvalho. Brasília: TCU, Secretaria de Controle Externo da Agricultura e do Meio Ambiente (SecexAmbiental), 2017.

BRUNDTLAND, Gro Harlem. Nosso futuro comum: comissão mundial sobre meio ambiente e desenvolvimento. 2.ed. Rio de Janeiro: Fundação Getúlio Vargas, 1991.

CANOTILHO, José Joaquim Gomes; LEITE, José Rubens Morato. Direito Constitucional Ambiental Brasileiro. São Paulo: Saraiva, 2007.

DALLARI, Dalmo de Abreu. Direitos humanos e Cidadania. São Paulo: Moderna, 2004.

FIORILLO, Celso Antônio Pacheco. Curso de direito ambiental brasileiro. 4. ed. São Paulo: Saraiva, 2003 apud SILVA, Maria Beatriz Oliveira da. O direito à qualidade de vida e o 
consumo sustentável como indicador da qualidade de vida. Revista do Curso de Direito da Faculdade da Serra Gaúcha, n. 5, 2009.

MICHAELIS. Dicionário Brasileiro da Língua Portuguesa. Disponível em: $<$ http://michaelis.uol.com.br/busca? $\mathrm{r}=0 \& \mathrm{f}=\mathrm{NaN} \& \mathrm{t}=\mathrm{NaN} \&$ palavra=saude $>$. Acesso em: $24 \mathrm{de}$ setembro de 2020.

NOHARA, Irene Patricia. Fundamentos de Direito Público. São Paulo: Atlas, 2016.

ONU. Declaração do Rio sobre Meio Ambiente e Desenvolvimento. Rio de Janeiro, 1992. Disponível em: <http://www.onu.org.br/rio20/img/2012/01/rio92.pdf> Acesso em: 16 de set 2020.

ORGANIZAÇÃO DAS NAÇÕES UNIDAS - ONU. Declaração de Estocolmo sobre o Meio Ambiente Humano. In: Anais Conferência das Nações Unidas sobre Meio Ambiente Humano. $\quad$ Estocolmo, $1972 . \quad$ Disponível em: http://www.direitoshumanos.usp.br/index.php/Meio-Ambiente/declaracao-de-estocolmosobre-o-ambiente-humano.html. Acesso em: 20 de setembro de 2020.

ORGANIZAÇÃO DAS NAÇÕES UNIDAS. Declaração de Estocolmo sobre o Meio Ambiente Humano. In: Anais Conferência das Nações Unidas sobre Meio Ambiente Humano. Estocolmo, 6p, 1972.

ORGANIZAÇÃO MUNDIAL DA SAÚDE - OMS. Constituição da Organização Mundial da Saúde. Documentos básicos, suplemento da $45^{\text {a }}$ edição, outubro de 2006 . Disponível em: <https://www.who.int/governance/eb/who_constitution_sp.pdf $>$. Acesso em: 20 de setembro de 2020.

PEREIRA. Jane Reis Gonçalves. Interpretação constitucional e direitos fundamentais: uma contribuição ao estudo das restrições aos direitos fundamentais na perspectiva da teoria dos princípios. Rio de Janeiro: Renovar, 2006.

RELATÓRIO BRUNDTLAN. Nosso Futuro Comum. Disponível em: <http://pt.scribd.com/doc/12906958/Relatorio-Brundtland-Nosso-Futuro-Comum-EmPortugues>. Acesso em: 20 de setembro de 2020.

RONDÔNIA. Lei Complementar $\mathrm{N}^{\circ} 1.051$, de 12 de dezembro de 2019. Disciplina a locação de imóveis sob medida, no âmbito da Administração Pública Estadual Direta e Indireta e dá nova redação ao artigo 30 da Lei Complementar Estadual $n^{\circ} 609$, de 18 de fevereiro de 2011 e acresce o artigo $6^{\circ}$-A ao Decreto-Lei $n^{\circ}$ 17, de 25 maio de 1982. Disponível em: $<$ http://ditel.casacivil.ro.gov.br/COTEL/Livros/Files/LC1051.pdf>. Acesso em: $25 \mathrm{de}$ setembro de 2020.

SILVA, Maria Beatriz Oliveira da. O direito à qualidade de vida e o consumo sustentável como indicador da qualidade de vida. Revista do Curso de Direito da Faculdade da Serra Gaúcha, n 5, 2009. Disponível em: <http://ojs.fsg.br/index.php/direito/article/view/240>. 
SOUZA, Maria Claudia da Silva Antunes de; Pasold, Cesar Luiz. A Sociedade e os Riscos do Consumismo. Revista Bonijuris I Ano 31 I Edição 658 I Jun/Jul 2019.

SOUZA, Maria Claudia da Silva Antunes de. 20 Anos de Sustentabilidade: Reflexões Sobre Avanços e Desafios. Revista da Unifebe (Online) 2012.

SOUZA, Maria Claudia da Silva Antunes de. Sustentabilidade Corporativa: Uma Iniciativa De Cunho Social Transformando o Meio Ambiente. Revista Jurídica vol. 04, ${ }^{\circ}$. 45, Curitiba, 2016.

ZYMLER, Benjamim; ALMEIDA, Guilherme Henrique de La Rocque. O controle externo das concessões de serviços públicos e das parcerias público privadas. Belo Horizonte: Fórum, 2005. 